\title{
Chilaiditi syndrome in a patient with urological problems: Incidental diagnosis on computed tomography
}

\author{
Cevahir Özer, $M D ;{ }^{*}$ Seda Zenger, $M D^{+}$ \\ ${ }^{\dagger}$ Nobel Surgical Medical Center, Division of Radiology, Adana, Turkey; ${ }^{*}$ Nobel Surgical Medical Center, Division of Urology, Adana, Turkey
}

Cite as: Can Urol Assoc J 2012;6(2):e75-76. hittp://dx.doi.org/10.5489/cuaj.11048

\section{Abstract}

A rare syndrome, Chilaiditi's syndrome is interposition of the colon only or with the small intestine in hepatodiaphragmatic area. It may be asymptomatic, but it may also present with symptoms, such as abdominal pain, nausea, vomiting, constipation and respiratory distress. We present a patient who was admitted with urological problems; he was incidentally diagnosed with Chilaiditi's syndrome.

\section{Introduction}

Chilaiditi's syndrome is caused by hepatodiaphragmatic interposition of colon and is usually asymptomatic. ${ }^{1}$ It is often detected by chance during radiological examination. It is estimated to occur in $0.25 \%$ to $0.28 \%$ of the general population. ${ }^{1,2}$ It occurs most often in males and its incidence increases with age. ${ }^{3}$ Rarely, its symptoms range from mild abdominal pain to acute intestinal obstruction. ${ }^{4}$

\section{Case repoprt}

A 66-year-old male was admitted to clinic with complaints of prostatism. The patient had a history of right pyelolithotomy for renal stones and extracorporeal shock wave lithotripsy for the residual stones. In addition, there was occasional medication use for symptomatic treatment of irritable bowel syndrome. Right renal stones and the incidental left adrenal tumour (incidentaloma) were found on computed tomography $(\mathrm{CT})$, without contrast for the detection of renal calculi a year ago. The patient then had an upper abdominal CT. Two renal stones on the lower pole of right kidney and a simple cyst on the upper pole of left kidney were found on CT. The adrenal incidentaloma that was previously described could not be visualized. Besides these findings, CT showed the hepatodiaphragmatic inter- position of transvers colon (Fig. 1), that was not previously reported. The patient, who had been treated with an alpha blocker for benign prostatic hyperplasia, did not accept the interventional treatment options for renal stones. The followup was planned for the renal cyst. The patient was referred to the gastroenterologist for the management of Chilaiditi's syndrome and was conservatively treated with counselling and dietary recommendations.

\section{Discussion}

Hepatodiaphragmatic interposition of the bowel loop was described by Demetrious Chilaiditi in 1910. ${ }^{1}$ A literature review revealed about 160 cases. $^{5}$ The radiological finding of hepatodiaphragmatic interposition of bowel segment, also known as Chilaiditi's sign, defines asymptomatic anatomical abnormality. When associated with symptoms, it is called Chilaiditi's syndrome. ${ }^{4}$

In symptomatic cases, gastrointestinal symptoms (such as nausea, vomiting, constipation, abdominal distention and right upper quadrant or epigastric pain) are present. In our patient, we did not predict that this syndrome was due to the lack of an abdominal complaint at admission. Respiratory distress, cardiac arrhythmia and serious complications, such as acute intestinal obstruction and volvulus of the colon, can be seen. In addition, cases have been reported that mimic renal colic. ${ }^{6}$

Diagnosis is usually by chance, with the patient undergoing a routine chest or abdominal plain film. ${ }^{3} \mathrm{CT}$ and/or ultrasonography are required for the differential diagnosis. In our case, the diagnosis was coincidental during the patient's last CT. The interposition may occur temporarily as a result of transient distention of the bowel.? Due to this possible association, we did not consider Chilaiditi's syndrome. We also did not have the patient's past CT scans.

In symptomatic cases, treatment is usually conservative. ${ }^{5,7}$ Conservative management includes bed rest, nasogastric and/or rectal decompression and liquid replacement. 


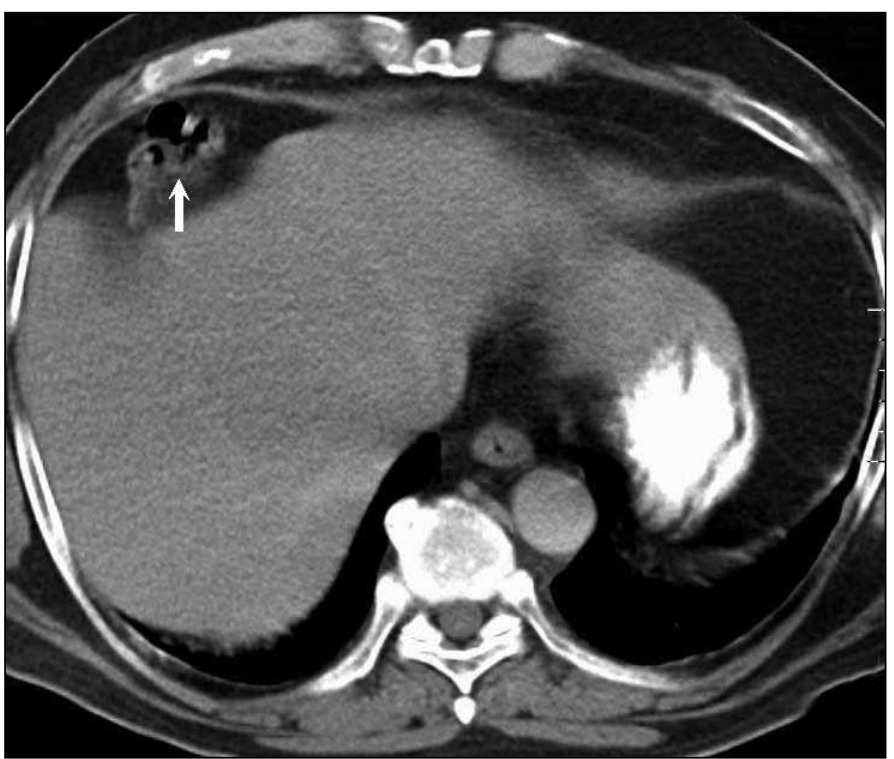

Fig. 1. The image showed interposition of colonic loop (arrow).

Surgical intervention (such as subtotal colectomy, peritoneal fixation of the colon, hepatopexy) may required in patients with persistent pain, refractory ileus, colonic volvulus or bowel ischemia. ${ }^{7,8}$ Patients with mild and intermittent abdominal complaints, like our patient, can be treated with counselling, dietary recommendations (higher consumption of fibre, increased fluid intake) and antispasmodic agents to support the intestinal functions.

\section{Conclusion}

Some diseases can be associated with urological problems or can mimic urological symptoms. Non-urinary abnormalities should be considered, while imaging results for urological problems should be evaluated.
Competing interests: None declared.

This paper has been peer-reviewed.

\section{References}

1. RD Glatter, April RS, Miskovitz P, et al. Severe recurrent abdominal pain: an anatomical variant of Chilaiditi's syndrome. MedGenMed 2007;9:67.

2. McNamara RF, Cusack S, Hallihan P. Chilaiditi's syndrome. West J Emerg Med 2009;10:250.

3. Chen SY, Liu CT, Isai YC, et al. Sigmoid volvulus associated Chilaiditi's syndrome. Rev Esp Enferm Dig 2007;99:482-3. http://dx.doi.org/10.4321/S1130-01082007000800017

4. Sorrentino D, Bazzocchi M, Badano L, et al. Heart-touching Chilaiditi's syndrome. World J Gastroenterol 2005;11:4607-9.

5. Yagnik VD. Chilaiditi syndrome with carcinoma rectum. Saudi J Gastroenterol 2011;17:85-6. http:// dx.doi.org/10.4103/1319-3767.74443

6. Angulo Cuesta J, Gonzales Zorraquino A, Unda Urzaiz M, et al. Chilaiditi syndrome in the differential diagnosis of renal colic. Arch Esp Urol 1991;44:300-1.

7. Hsu HL, Liu KL. Hepatodiphragmatic interposition of the colon. CMAJ 2011;183:E132. http://dx.doi. org/10.1503/cmaj.092117

8. Orangio GR, Fazio VW, Winkelman E, et al. The Chilaiditi sydrome and associated volvulus of the transvers colon. An indication of for surgical therapy. Dis Colon Rectum 1986;29:653-6. http://dx.doi. org/10.1007/BF02560330

Correspondence: Dr. Cevahir Özer. Nobel Surgical Medical Center, Kenan Evren Boulevard No: 45, 01170, Cukurova/Adana, Turkey; mdcevahir@yahoo.com 